\title{
Corrections
}

\section{On the identity of Aleochara (Coprochara) pauxilla (MULSANT \& REY, 1874) (Coleoptera: Staphylinidae)}

\section{CHRISTAN MAUS}

In the conclusions chapter of the above publication (Beitr. Ent. 51 (2001) 1, p. 228), the synonymy of the taxa dealt with is tabulated in a misleading way. Correctly, Baryodma pauxilla MULSANT \& REY, 1874 is a synonym of Aleochara verna SAY, 1836, whereas Aleachara pauxilla auct. nec MULSANT \& REY, 1874 is conspecific with Aleochara binotata KRAATZ, 1856.

The list of synonyms is thus to be read as follows:

Aleochara verna SAY, 1836: 156

Aleochara pauxilla MULSANT \& REY, 1874: 443, new synonymy

Aleochara binotata KRAATZ, 1856: 106

Aleochara pauxilla auct. nec MULSANT \& REY, 1874

\author{
Author's address: \\ Dr. ChristIAN MAUS \\ Institute for Environmental Biology \\ Bayer AG, Crop Protection, Building 6620 \\ Research Center Monheim \\ D-51368 Leverkusen \\ Germany \\ e-mail: christian.maus@web.de
}

